\title{
Fluorescent carbon-dots enhance light harvesting and photosynthesis by overexpressing PsbP and PsiK genes
}

Yuhui Wang ${ }^{1+}$, Zhuomi Xie ${ }^{2,3+}$, Xiuhua Wang $^{1}$, Xin Peng $^{2^{*}}$ and Jianping Zheng ${ }^{\text {* }^{*}}$

\begin{abstract}
Background: Fluorescent carbon-dots (CDs) with multifaceted advantages have provided hope for improvement of crop growth. Near infrared (NIR) CDs would be more competitive and promising than short-wavelength emissive CDs, which are not directly utilized by chloroplast. The molecular targets and underlying mechanism of these stimulative effects are rarely mentioned.

Results: NIR-CDs with good mono-dispersity and hydrophily were easily prepared by a one-step microwave-assisted carbonization manner, which showed obvious UV absorptive and far-red emissive properties. The chloroplast-CDs complexes could accelerate the electron transfer from photosystem II (PS II) to photosystem I (PS I). NIR-CDs exhibited a concentration-dependent promotion effect on N. benthamiana growth by strengthening photosynthesis. We firstly demonstrated that potential mechanisms behind the photosynthesis-stimulating activity might be related to up-regulated expression of the photosynthesis and chloroplast synthesis related genes, among which PsbP and PsiK genes are the key regulators.
\end{abstract}

Conclusion: These results illustrated that NIR-CDs showed great potential in the applications to increase crop yields through ultraviolet light harvesting and elevated photosynthesis efficiency. This work would provide a theoretical basis for the understanding and applications of the luminescent nanomaterials (not limited to CDs) in the sunlight conversion-related sustainable agriculture.

Keywords: Fluorescent carbon-dots, Photosynthesis, N. benthamiana, PsbP, PsiK

\section{Background}

Photosynthesis is one of the most fundamental biochemical processes of organisms, and it is vital to the plant growth on earth. Enhancing photosynthetic efficiency and electron transfer process are thought to be one of the efficient approaches for improving plant growth

\footnotetext{
*Correspondence: pengx@nit.zju.edu.cn; zhengjianping@nimte.ac.cn

†Yuhui Wang and Zhuomi Xie have contributed equally to this work

${ }^{1}$ Cixi Institute of Biomedical Engineering, Ningbo Institute of Materials

Technology and Engineering, Chinese Academy of Sciences,

Ningbo 315300, People's Republic of China

${ }^{2}$ Ningbo Research Institute of Zhejiang University, Ningbo 315100,

People's Republic of China

Full list of author information is available at the end of the article
}

[1]. Many strategies such as gene regulation [2], genetic improvement [3] and environmental modelling [4] have been applied to improve the photosynthetic efficiency in crops. In the photosynthesis process, sunlight utilization by chloroplasts of plants is limited to visible spectral range [5]. Therefore, it is very promising to build an artificial hybrid photosynthesis system to improve the ability of plants to capture and convert solar energy efficiently [6].

Luminescent nanomaterials (LNMs) have been paid more attention in many fields like chemo/biosensing, bioimaging, catalysis and nanomedicine due to their unique photophysical properties [7]. As light conversion agents, LNMs would have the potential to enhance sunlight original author(s) and the source, provide a link to the Creative Commons licence, and indicate if changes were made. The images or other third party material in this article are included in the article's Creative Commons licence, unless indicated otherwise in a credit line to the material. If material is not included in the article's Creative Commons licence and your intended use is not permitted by statutory regulation or exceeds the permitted use, you will need to obtain permission directly from the copyright holder. To view a copy of this licence, visit http://creativecommons.org/licenses/by/4.0/. The Creative Commons Public Domain Dedication waiver (http://creativeco mmons.org/publicdomain/zero/1.0/) applies to the data made available in this article, unless otherwise stated in a credit line to the data. 
harvesting and promote photosynthesis efficiency [8]. In previous reports, semiconductor quantum dots (SQDs) [9], silicon quantum dots [10], lanthanide-doped up-conversion phosphors [11] and noble metal nanoclusters [12] were exploited on the plant growth and development. However, toxicity of the heavy metal ions, high cost and low fluorescence quantum yield greatly limit their further applications $[13,14]$. Therefore, it is meaningful and challenging to seek new LNMs with the features of low cost, good biocompatibility and outstanding optical properties [15].

Recently, fluorescent carbon-dots (CDs) emerging as a new class of inorganic phosphors have attracted increasing attention [16-19]. Due to their obvious merits of facile and cheap preparation, excellent fluorescence characters, CDs have demonstrated many promising applications such as chemo/biosensing, bioimaging, catalysis, and optoelectronic devices [20-24]. Specially, most of the reported CDs are no/low toxic and biocompatible, and have been demonstrated great potential in biologicalrelevant fields [25]. However, some CDs with positive charge reveal cyto and geno-toxicity in some degree [26]. The biosafety of the longtime exposure to CDs remains to be a challenging issue, and should be taken into consideration [27]. The development of CDs in photosynthesis has become a hot research topic [28-33]. For instance, Chandra et al. reported a blue-emissive CDs-chloroplasts hybrid nanosystem to accelerate electron transfer from CDs to chloroplast [34]. Li et al. reported a strategy to enhance photosynthetic efficiency via light-harvesting with dual-emissive CDs [35]. Nonetheless, most of the CDs show short-wavelength blue/green emission, which is not directly utilized by chloroplast. To overcome the above issue, far-red emissive CDs with high quantum yield and good water-solubility were synthesized, and have demonstrated to be efficient in the enhancement of plant growth and photosynthesis [36]. Meanwhile, former researches have presented that CDs were no phytotoxicity on the growth of plants, and could be transferred from the roots to the stems and leaves through the vascular system [37]. The above reports confirmed that CDs would be competitive and promising agents to enhance photosynthesis or improve growth of crops. Nonetheless, the underlying mechanisms of these stimulative effects were hardly mentioned. There are few reports about the influence of CDs on the expression level of genes and the plant quality. [8]

Herein, in order to understand the mechanism of CDs-caused enhancive photosynthesis efficiency, representative near-infrared (NIR) emissive CDs (a model light-conversion phosphors) and Nicotiana benthamiana ( $N$. benthamiana, taken as a plant model) were preferentially selected, respectively. The NIR-CDs were verified to be effective in the enhancement of ultraviolet light absorption and the electron transfer from CDs to the chloroplasts $N$. benthamiana. So, improved photosynthetic efficiency was observed both in vivo and in vitro. Furthermore, some photosynthetic and chloroplast synthesis-relevant genes were inspected. The results demonstrated that $P s b P$ and $P s i K$ genes were the key regulators of the photosynthesis-stimulating effect that activated by the NIR-CDs. To the best of our knowledge, this is the first mechanism research on the genes level, which provides a manner to study the mechanism of LNMsinduced enhanced sunlight absorption and photosynthesis efficiency. In addition, this work would provide a theoretical basis for the understanding and applications of other luminescent nanomaterials (not limited to CDs) in the sunlight conversion-related sustainable agriculture.

\section{Results}

\section{Characterizations of the CDs}

The NIR-CDs were facilely synthesized by a microwaveassisted carbonization method using glutathione and formamide as the raw materials. To characterize the morphology, structure and surface state of the prepared CDs, TEM, XRD, FT-IR, XPS, Raman and Zeta potential measurements were performed. As shown in Fig. 1a, the harvested NIR-CDs exhibit uniform and spherical morphologies with narrow size distribution and an average diameter of $3.8 \mathrm{~nm}$. However, no obvious lattice fringes are observed in the HR-TEM image (Fig. 1b), implying that they are mostly noncrystalline. A typical peak at $26^{\circ}$ [(002) plane] in the XRD pattern (Fig. 1c) further verifies the noncrystalline graphite structure of the CDs [38]. Typical Raman spectrum (Additional file 1: Figure S1) also confirms the graphite nature of the NIR-CDs. The distinct peaks at 1557 and $1321 \mathrm{~cm}^{-1}$ represent the typical G-band and D-band, respectively. Meanwhile, a low ratio of $D$ to $G$ strongly attests the existence of pristine carbon in the NIR-CDs [39]. In Fig. 1d, a broad and strong absorption band from 3000 to $3700 \mathrm{~cm}^{-1}$ with two peaks centered at 3435 and $3189 \mathrm{~cm}^{-1}$ is clearly observed, which is attributed to the stretching vibrations of $\mathrm{O}-\mathrm{H}$ and $\mathrm{N}-\mathrm{H}$, demonstrating the existence and abundance of hydrophilic hydroxyl and amino groups. The peaks at $1674,1579,1389 \mathrm{~cm}^{-1}$ belong to the stretching vibrations of the $\mathrm{C}=\mathrm{O}, \mathrm{C}=\mathrm{C} / \mathrm{C}=\mathrm{N}$, and $\mathrm{C}-\mathrm{N}$ bonds, respectively. The peaks at 1158 and $1241 \mathrm{~cm}^{-1}$ are attributed to $\mathrm{C}-\mathrm{O}$ and $\mathrm{C}-\mathrm{N}$ stretching vibrations. The absorption band at $1000-1100 \mathrm{~cm}^{-1}$ is attributed to $\mathrm{C}=\mathrm{S}$ and oxidized $S$ bonds $[40,41]$. These FT-IR assignments are clearly verified by XPS analysis (Fig. 1e). Representative peaks of $\mathrm{C} 1 \mathrm{~s}, \mathrm{~N} 1 \mathrm{~s}, \mathrm{O} 1 \mathrm{~s}$, and $\mathrm{S} 2 \mathrm{p}$ are observed at 283, 397, 529, $161 \mathrm{eV}$, respectively, which indicates that the CDs mainly contain $\mathrm{C}, \mathrm{N}, \mathrm{O}$ and $\mathrm{S}$ elements (atom 

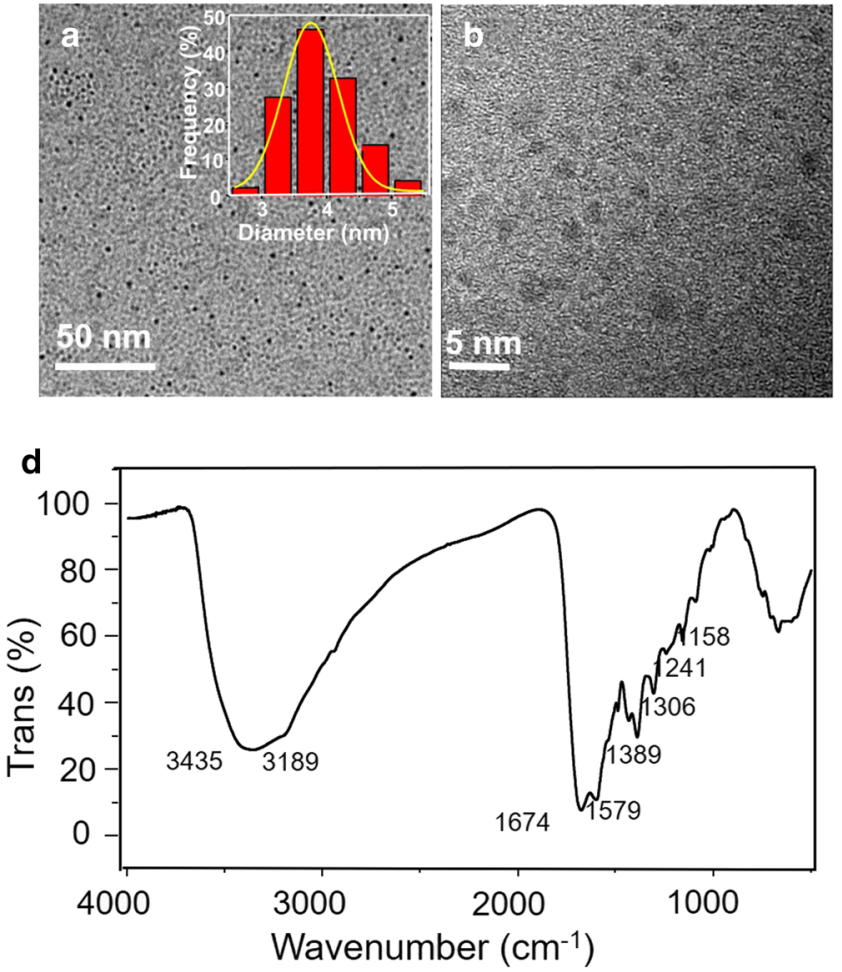
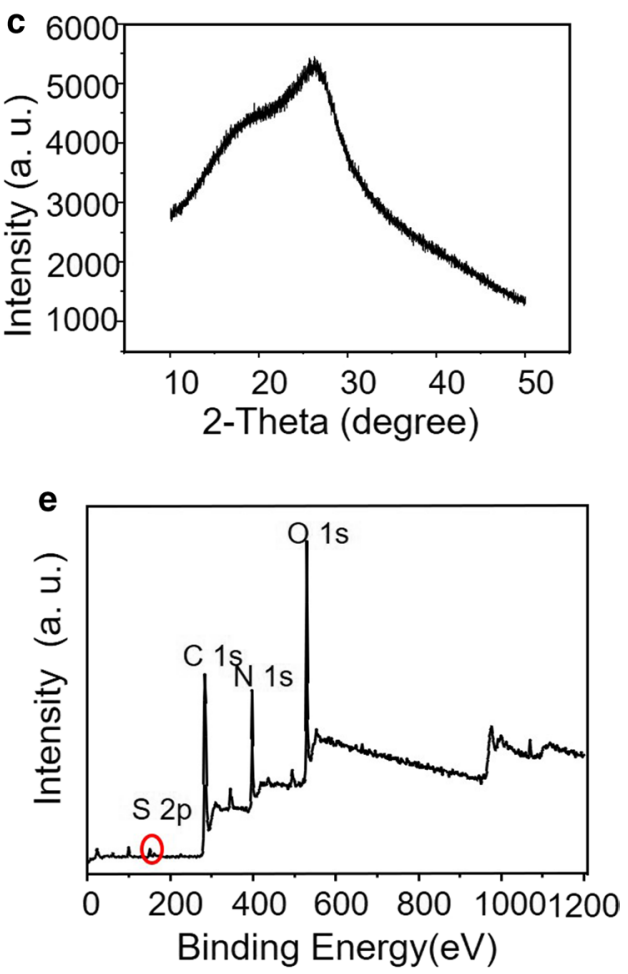

Fig. 1 a TEM image of the NIR-CDs (inset: the corresponding TEM histogram and Gauss fitting of particle size distribution). HR-TEM (b), XRD pattern (c), FT-IR spectrum (d) and XPS (e) measurements of the NIR-CDs

ration, $\mathrm{C}: \mathrm{O}: \mathrm{N}: \mathrm{S}=63.61: 16.77: 19.28: 0.34)$. High resolution C 1 s spectrum (Additional file 1: Figure S2a) shows five peaks at 284.8, 286.3, 288, 289.4 and $291.2 \mathrm{eV}$, corresponding to $\mathrm{C}=\mathrm{C} / \mathrm{C}-\mathrm{C}, \mathrm{C}-\mathrm{N}, \mathrm{C}-\mathrm{O}, \mathrm{C}=\mathrm{N} / \mathrm{C}=\mathrm{O}$, and $\mathrm{N}-\mathrm{C}=\mathrm{O}$, respectively. Three unique peaks of pyridinelike $\mathrm{N}$, amino $\mathrm{N}$, and pyrrolelike $\mathrm{N}$ at 398.6, 400.1, and $402.5 \mathrm{eV}$ are observed in high resolution $\mathrm{N} 1 \mathrm{~s}$ spectrum (Additional file 1: Figure S2b). O $1 \mathrm{~s}$ XPS spectrum exhibit the typical peaks of $\mathrm{C}-\mathrm{OH}$ and $\mathrm{C}=\mathrm{O}$ at 531.5 and $533.7 \mathrm{eV}$, respectively (Additional file 1: Figure S2c). In addition, the higher solution $\mathrm{S} 2 \mathrm{p}$ spectrum (Additional file 1: Figure S2d) can be fitted with four binding energies of 162.2, 163.6, 164.7 and 168.7, which are assigned to thiolate, $2 \mathrm{p}_{3 / 2}$ and $2 \mathrm{p}_{1 / 2}$ of thiophene $\mathrm{S}$, and oxidized $\mathrm{S}$, respectively $[42,43]$. Zeta potential measurement reveals that the NIR-CDs are negatively charged $(\zeta=-15.8 \mathrm{mV}$, Additional file 1: Figure S3), which would enable strong electrostatic exclusion and colloid stability.

Next, the photophysical properties of the NIR-CDs were investigated in detail. Figure 2a represents the UVVis absorption spectrum. The NIR-CDs present three main absorption bands i.e., $240-300 \mathrm{~nm}, 350-450 \mathrm{~nm}$, and $550-750 \mathrm{~nm}$, which are generally assigned to the typical $\pi \rightarrow \pi^{*}$ transition of the aromatic $C=C$ bond, $\pi \rightarrow \pi^{*}$ and $n \rightarrow \pi^{*}$ transitions of the aromatic $\pi$ system containing the $\mathrm{C}=\mathrm{O}, \mathrm{C}=\mathrm{N}$, and $\mathrm{C}=\mathrm{S}$ bonds, respectively [44]. As shown in Fig. 2b, the CDs display brightly deep-red emission from 625 to $710 \mathrm{~nm}$ with a sharp peak centered at $680 \mathrm{~nm}$. And an excitation-independent fluorescence emission property of the NIR-CDs is observed distinctly. The fluorescence excitation spectrum indicates that the excitation focuses on blue spectrum range with the optimal excitation wavelength of $420 \mathrm{~nm}$. Moreover, the averaged lifetime is measured and calculated to be 2.8 ns with bi-exponential decays (Additional file 1: Figure S4), and the absolute fluorescence quantum yield of the NIR-CDs is measured to be $17.8 \%$ under the optimal excitation i.e., $420 \mathrm{~nm}$. In addition, photostability of the NIR-CDs was estimated. In Additional file 1: Figure S5, the emission intensities slightly decrease upon the irradiation of ultraviolet lamp, implying good tolerance to photobleaching of the NIR-CDs. The CDs solution keeps very stable fluorescence emission even after one month storage at ambient environment (Additional file 1: Figure S6). So, the above unique optical properties e.g., strong absorption in the ultraviolet-blue region, efficient and stable emission in far-red region make this NIR-CDs promising agent in light-harvesting and electron transfer from photosystem II (PS II) to photosystem I (PS I) in chloroplasts. 

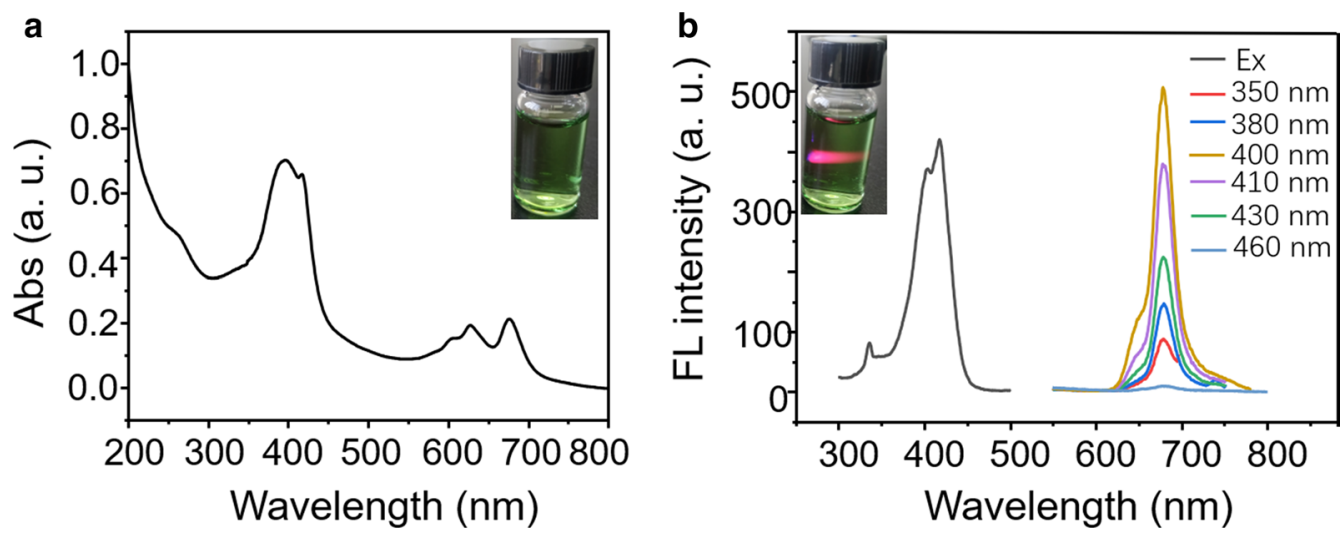

Fig. 2 a UV-vis absorption spectrum of the NIR-CDs dissolved in water $(100 \mu \mathrm{g} / \mathrm{mL})$, inset: digital photograph of the NIR-CDs solution under daylight. b Fluorescence excitation spectrum (black line) and emission spectra under varying excitation wavelengths of the NIR-CDs solution $(10 \mu \mathrm{g} / \mathrm{mL})$, inset: digital photograph of the NIR-CDs under the excitation of laser pointer $(405 \mathrm{~nm})$

\section{NIR-CDs treatment significantly promoted the growth and development of $N$. benthamiana}

$N$. benthamiana were cultured with different concentrations of NIR-CDs solution (experiment group) and pure water (control group), respectively. Figure 3 is the photograph of $N$. benthamiana exposed to different concentrations of NIR-CDs during 5 days. As shown in it, there is an obvious difference of growth vigour of $N$. benthamiana between the control group and CDs-treated groups. A concentration-dependent promotion effect on $N$. benthamiana growth was found in the concentration range of NIR-CDs from 0 to $0.1 \mathrm{mg} / \mathrm{mL}$. It turned out that a concentration threshold $(0.3 \mathrm{mg} / \mathrm{mL})$ was presented, above which the differences were not significant. $0.05 \mathrm{mg} / \mathrm{mL}$ of the CDs was the optimum concentration.

In order to obtain accurate results, root length, stem length, leaf area and biomass were measured at least three times, respectively. As shown in Fig. 4, it could be found that both the stem and root elongation depended on the concentration of NIR-CDs. The stem length of $N$. benthamiana exposed to the CDs (0.01 mg/mL, $0.05 \mathrm{mg} / \mathrm{mL}, 0.1 \mathrm{mg} / \mathrm{mL}$ and $0.3 \mathrm{mg} / \mathrm{mL}$ ) was longer $44.83 \pm 3.9 \%, \quad 143.1 \pm 9.8 \%, \quad 32.76 \pm 4.1 \%$ and $37.93 \pm 3.7 \%$ than the control, respectively. As for the elongation of root length, they were $26.28 \pm 3.4 \%$, $62.37 \pm 6.8 \%, 38.14 \pm 4.5 \%$ and $32.98 \pm 4.3 \%$, respectively. The leaf area exposed to CDs $(0.01 \mathrm{mg} / \mathrm{mL}$, $0.05 \mathrm{mg} / \mathrm{mL}, 0.1 \mathrm{mg} / \mathrm{mL}$ and $0.3 \mathrm{mg} / \mathrm{mL}$ ) was increased by $14.54 \pm 2.2 \%, \quad 57.27 \pm 4.6 \%, \quad 29.94 \pm 2.5 \%$, and $12.72 \pm 0.9 \%$ than the control, respectively. When the concentration was $0.3 \mathrm{mg} / \mathrm{mL}$, NIR-CDs didn't stimulate the growth of $N$. benthamiana anymore. $0.05 \mathrm{mg} /$ $\mathrm{mL}$ of CDs improved root length, stem length and biomass prominently, which was the optimal concentration for the growth of $N$. benthamiana, with a growth rate of single plant fresh weight of $247.03 \pm 26 \%$. To further evaluate the metabolic activity of $N$. benthamiana under the treatment of different concentrations of NIRCDs, the SOD activity was also investigated with the results shown in Fig. 4e. CDs at $0.01 \mathrm{mg} / \mathrm{mL}, 0.05 \mathrm{mg} /$ $\mathrm{mL}, 0.1 \mathrm{mg} / \mathrm{mL}$, and $0.3 \mathrm{mg} / \mathrm{mL}$ significantly increased SOD activity by $5.88 \pm 0.6 \%, 58.82 \pm 5.9 \%, 23.52 \pm 3.2 \%$ and $29.41 \pm 3.2 \%$ respectively, as compared to the control group.

\section{Process of uptake and transmission of NIR-CDs in N. benthamiana}

In order to study the uptake and translocation conditions of NIR-CDs in N. benthamiana during the growth stage, confocal images of root, stem, and leaf were displayed using Laser-scanning confocal fluorescence microscope after 5 days incubation with $0.05 \mathrm{mg} / \mathrm{mL}$ CDs. As shown in Fig. 5, the uptake of NIR-CDs by $N$. benthamiana could be identified in vivo due to the red luminescent emissions from CDs observed under $514 \mathrm{~nm}$ excitation. The bright field images were also investigated and overlain with luminescence images. In contrast, no red luminescence and any autofluorescence background of tissue were detected in the control group. The distribution of luminescence signals of CDs predominantly existed in the roots, and less in stems and leaves, revealing that CDs were absorbed by root and transported to the stems and leaves.

The confocal images also revealed that the CDs could penetrate cell wall into vascular bundle system. Thus, the growth-promoting effect of CDs might be due to the entry of CDs into plant cells to regulate plant physiological activities. 


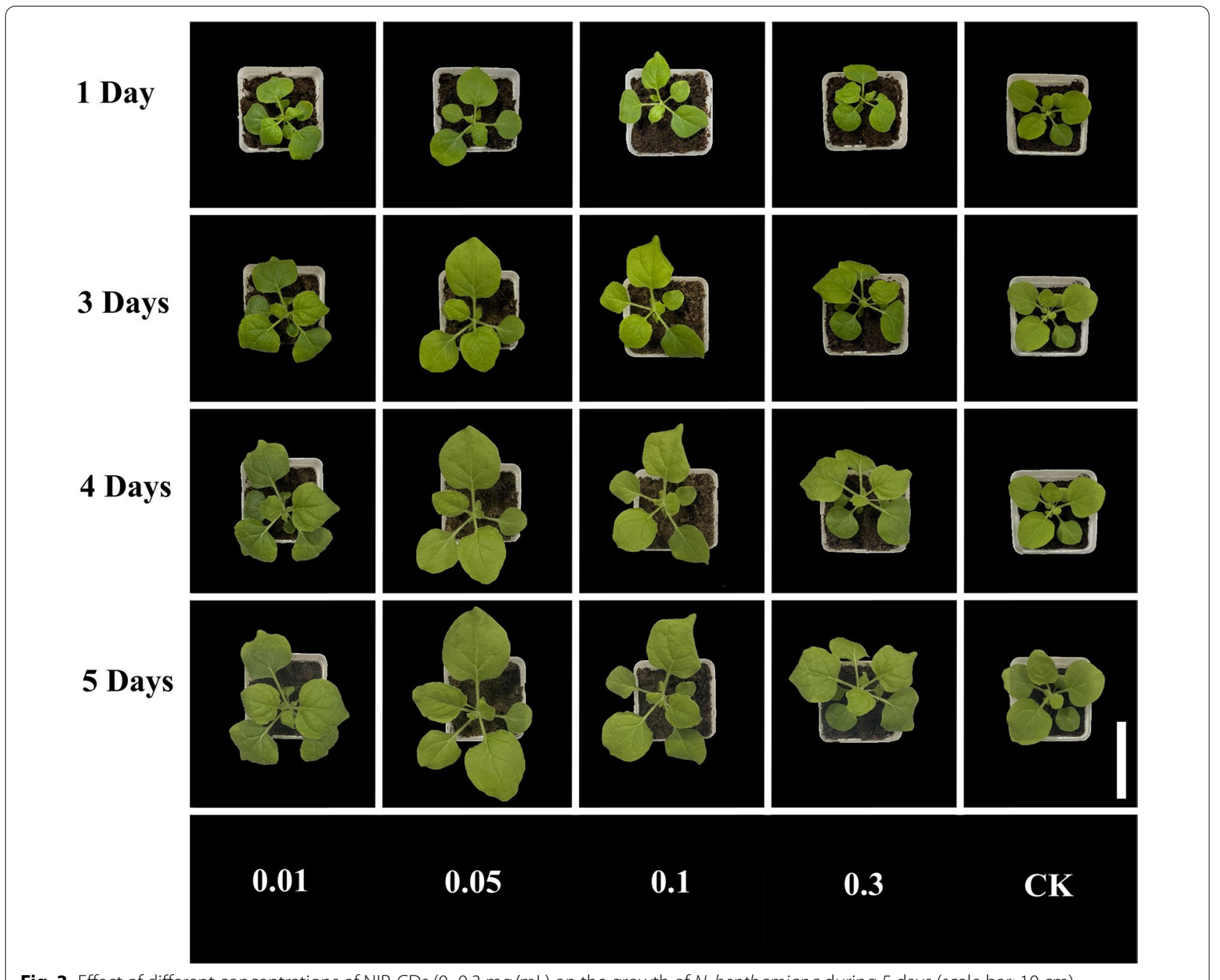

Fig. 3 Effect of different concentrations of NIR-CDs $(0-0.3 \mathrm{mg} / \mathrm{mL})$ on the growth of $\mathrm{N}$. benthamiana during 5 days $(\mathrm{scale}$ bar: $10 \mathrm{~cm}$ )

\section{NIR-CDs treatment significantly improved chlorophyll content and photosynthesis}

The effect of NIR-CDs treatment on photosynthesis was determined. $0.05 \mathrm{mg} / \mathrm{mL}$ of NIR-CDs enhanced chlorophyll content by $11.4 \%, 6.08 \%$, and $10.21 \%$ in seven-leaf, ten-leaf, and thirteen-leaf stage, respectively $(P<0.05)$. CDs treatment induced significant increase in net photosynthetic rate at all the three stages, and the maximum increase $(66.68 \%$ ) was achieved by $0.05 \mathrm{mg} / \mathrm{mL}$ of CDs in thirteen-leaf stage. The rate of photosynthesis, which is evaluated by $\mathrm{CO}_{2}$ entry through the stomata and fixation within the chloroplast, can change when plants are subjected to various treatments. Exposure to CDs at $0.05 \mathrm{mg} / \mathrm{mL}$ significantly increased the transpiration rate by $0.15-1.47 \%$, stomatal conductance by $17.5-110.8 \%(P<0.01)$ and intercellular $\mathrm{CO}_{2}$ by $20.38-$ $33.82 \%(P<0.01)$ as compared to the control group (Fig. 6).

\section{Growth-promoting effect of NIR-CDs were achieved} by upregulating expression level of the genes involved in photosynthesis

The increased growth rate might be due to NIR-CDs stimulating the photosynthesis of $N$. benthamiana seedlings. To prove the conjecture, we investigated the effects of NIR-CDs on the gene expression level, which were involved in photosynthesis. In this work, eight major photosynthetic genes ( $P s i-K, P s b P, P s b S 1, P s b Y$, HCF136, PsbQ1, PsbQ2, and PsbO4) of N. benthamiana were examined after 5 days incubation with $0.05 \mathrm{mg} / \mathrm{mL}$ NIR-CDs. The primers of these candidate genes and reference gene are displayed in Table 1 . The results shown in Fig. 7 indicated that the CDs could activate significantly the overexpression of seven $N$. benthamiana photosynthetic genes compared with control group. Furthermore, the expression levels of $P s b P$ and $P s i-K$ genes were increased the most by 48 -fold and 32 -fold as compared 

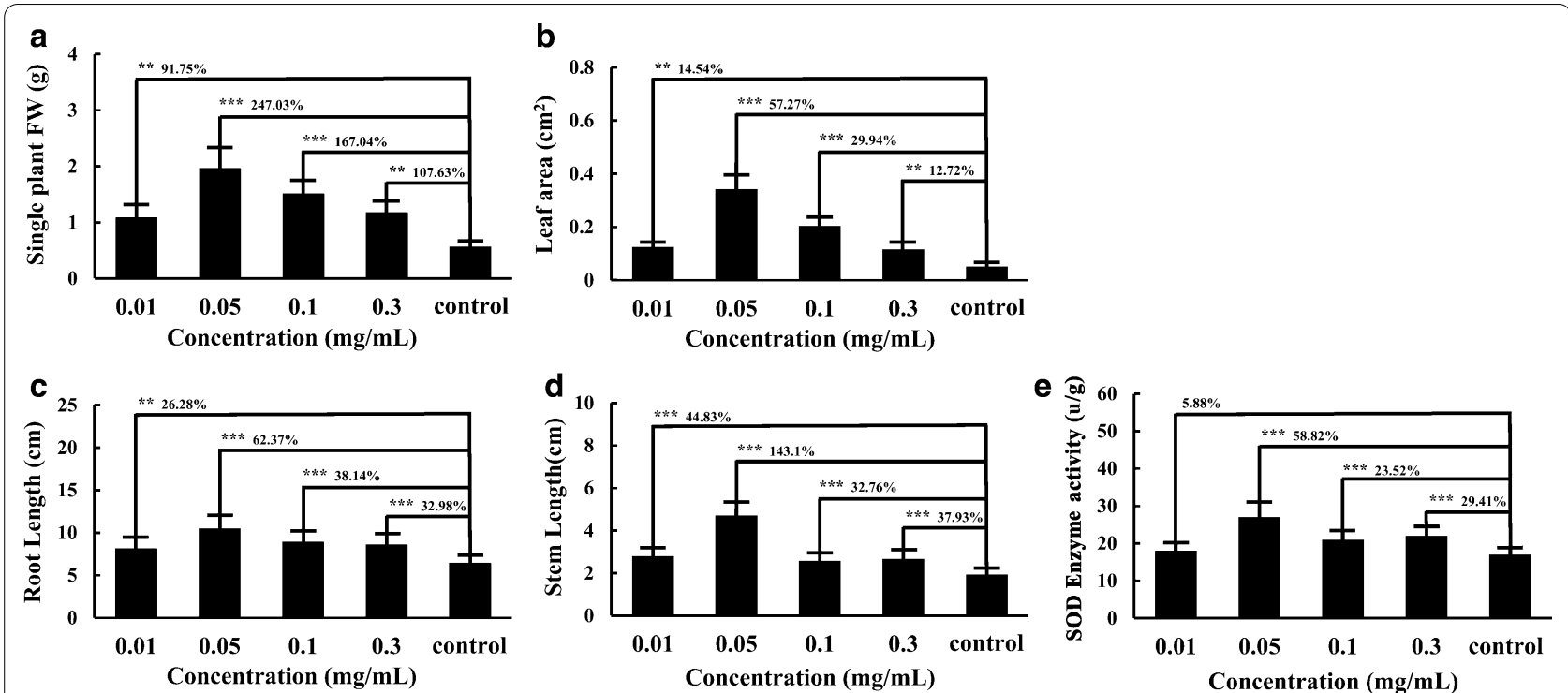

Fig. 4 Growth potential indexes of different concentrations of NIR-CDs (0-0.3 mg/mL) treatment after 5 days, compared to the control. a Single plant fresh weight (FW) of N. benthamiana. $\mathbf{b}$ Leaf area. $\mathbf{c}$ Root length. $\mathbf{d}$ Stem length. e SOD activity. All the experiments were repeated three times at least. Marked with ${ }^{*} P<0.05,{ }^{*} P<0.01$ and ${ }^{* *} P<0.001$ exhibit significant differences from control, respectively

to the control, respectively. It revealed that $P s b P$ and $P s i-K$ genes were most sensitive to the stimulation effect of NIR-CDs. At the concentration of $0.05 \mathrm{mg} / \mathrm{mL}$ NIRCDs, the expression levels of the five genes (PsbS1, PsbY, $P s b Q 1, P s b Q 2$, and PsbO4) were significantly increased by $148.3 \%, 246.7 \%, 90.3 \%, 98.4 \%$, and $294.4 \%$, respectively after incubation of 5 days. In addition, there were no significant differences in the expression level of HCF136, which suggested NIR-CDs had no significant effects on $H C F$ family genes. These results coincided with the response of the chlorophyll content and photosynthetic rate.

\section{Discussion}

Enhanced sunlight harvesting and photosynthesis efficiency of the CDs- chloroplast hybrids in vitro

Generally, far-red radiation can promote the growth of plant [45]. Herein, in order to verify the NIR-CDsinduced enhanced photosynthesis, interaction between the CDs and chloroplast, and the classical Hill reaction were severally studied. In Fig. 8a, the isolated chloroplast suspension shows two obvious absorption bands i.e., 400-500 and 650-700 nm. But, after being covered with the CDs, the absorption of chloroplast-CDs complexes is broadened and enhanced remarkably, especially in UV region (350-400 $\mathrm{nm}$ ), which is mainly attributed to the typical UV absorption property of NIR-CDs (Fig. 2a). So, the hybrid chloroplast-CDs photosystem would be much more efficient in the harvesting of solar light. As shown in Fig. 8b, fluorescence emissions of the CDs gradually decrease along with the constant addition of chloroplast, implying relatively strong adsorption between each other. Considering good spectrum overlap $(650-700 \mathrm{~nm})$ between fluorescence emission of the NIR-CDs and absorption of chloroplast, we speculate that the reason for the above fluorescence quenching is the occurrence of energy transfer from the CDs to chloroplast $[36,46]$.

As mentioned above, the NIR-CDs possess an obvious UV absorption feature, and their fluorescence emissions overlap well with the absorption of chloroplasts in the far-red region. So, it is possible and desirable that the NIR-CDs can absorb and transform rarely-used UV radiation to highly utilized far-red light to enhance photosynthesis efficiency. To authenticate this hypothesis, a typical Hill reaction was performed. Hill reaction provide a facile method to research the light-dependent transfer of electrons by chloroplasts in photosynthesis that results in the cleavage of water molecules and liberation of oxygen $[47,48]$. Owing to the strong capacity of electron capture, 2,6-dichlorophenolindophenol (DCPIP) is routinely used as an indicator to monitor the electrons transfer from PS II to PS I during the photoreaction process. The absorption alterations at $600 \mathrm{~nm}$ indicate the reduction of DCPIP. By this way, the photosynthesis rate was estimated through measuring the absorption change of DCPIP. In this study, a xenon lamp was adopted as the light source. As shown in Fig. 8c, upon the durative exposure, the absorption of DCPIP decreases obviously, suggesting the emergence of photosynthesis of the subjected chloroplasts. Compared with the isolated chloroplasts, 


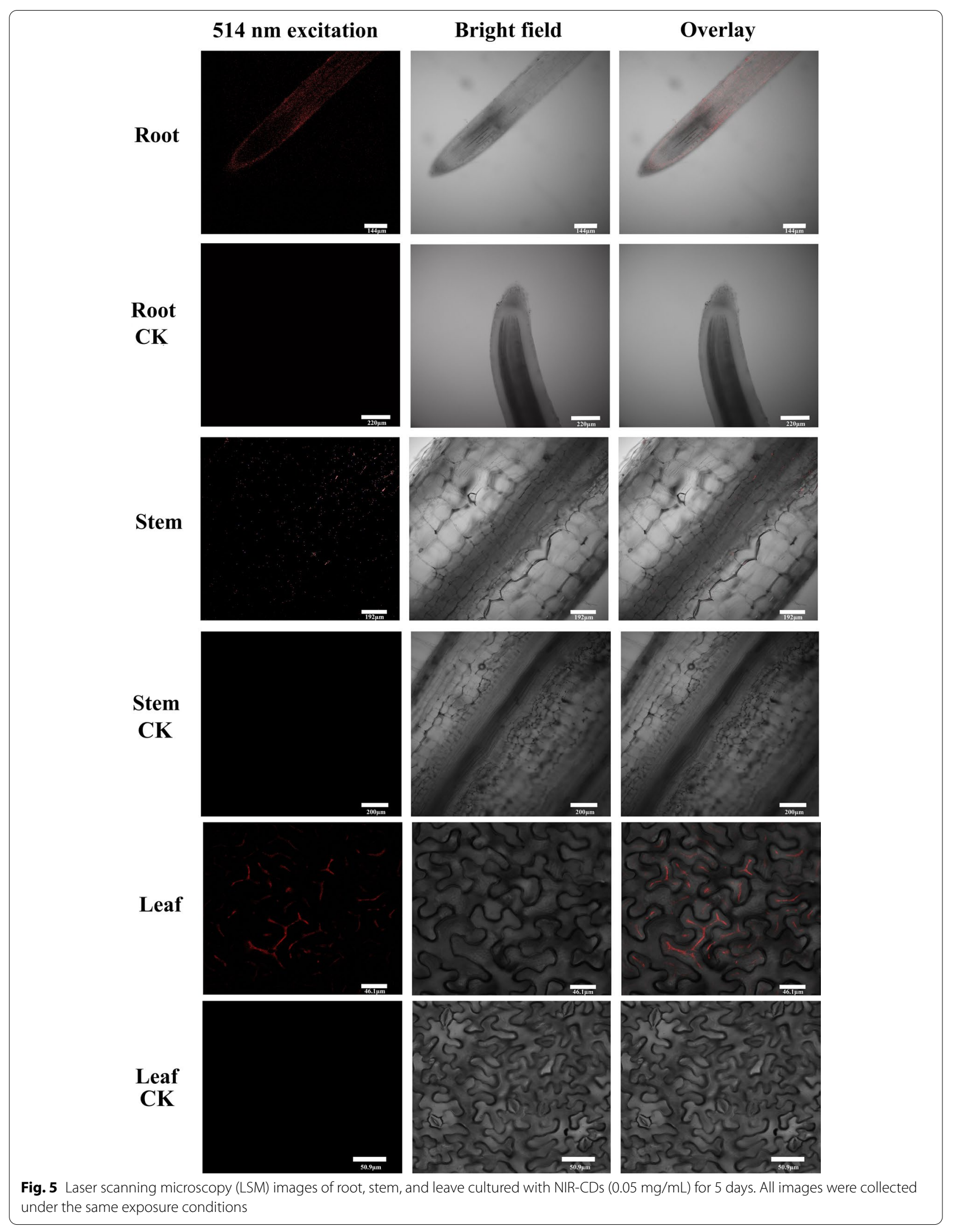




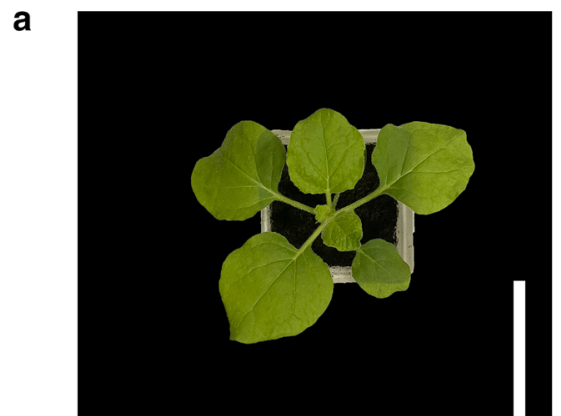

Seven-leaf stage

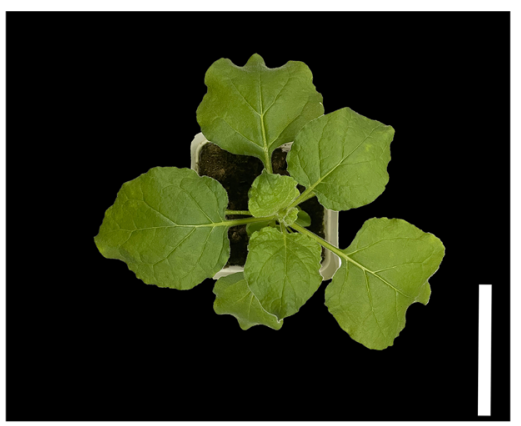

Ten-leaf stage

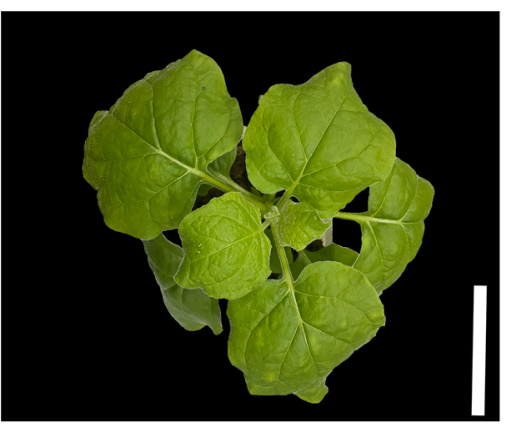

Thirteen-leaf stage

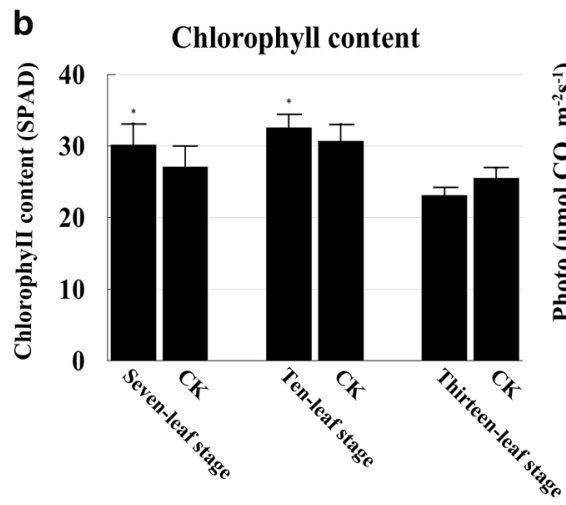

Net photosynthetic rate

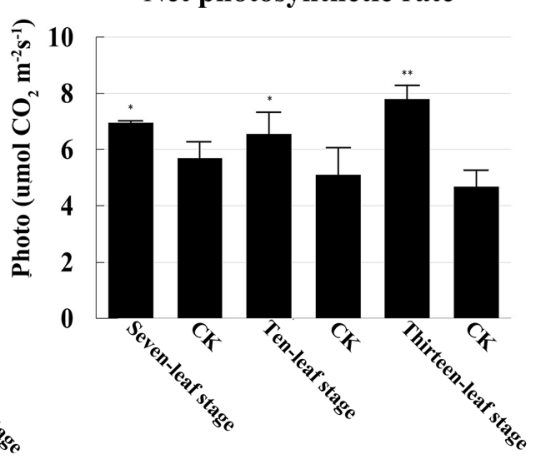

Stomatal conductance
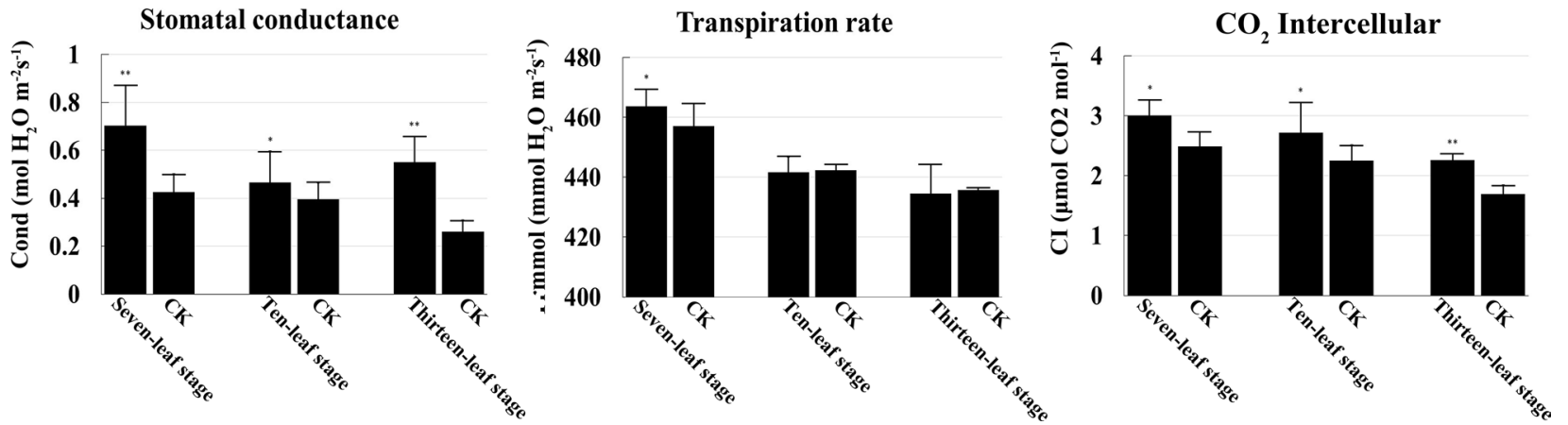

Fig. 6 The phenotype and photosynthetic parameters of $\mathrm{N}$. benthamiana seedlings exposed to $0.05 \mathrm{mg} / \mathrm{mL}$ of NIR-CDs in seven-leaf, ten-leaf, and thirteen-leaf stage respectively. a The phenotype of $N$. benthamiana seedlings growth (scale bar: $10 \mathrm{~cm}$ ). $\mathbf{b}$ The chlorophyll content, net photosynthetic rate, intercellular $\mathrm{CO}_{2}$ concentration, transpiration rate and stomatal conductance of $\mathrm{N}$. benthamiana seedlings. Marked with ${ }^{*} P<0.05,{ }^{* *} P<0.01$ exhibit significant differences from control, respectively

all the complexes of NIR-CDs-chloroplast can accelerate the reduction of DCPIP, and absorb and transform more UV light to far-red light that can be directly utilized by chloroplast. Thus, in the hybrid photosystem, the adoption of NIR-CDs is favorable for the light harvesting and utilization of chloroplasts in photosynthesis. Moreover, it is clearly to observe that the optimum concentration of the NIR-CDs is $50 \mu \mathrm{g} / \mathrm{mL}$ for the achievement of the highest photosynthesis rate. The above results obviously demonstrate that the proposed NIR-CDs show enhanced light harvesting in UV region, and their near infrared emissions would further promote the electrons transfer process from PS II to PS I, thereby improving the photosynthesis efficiency in vitro.

\section{NIR-CDs strengthen photosynthesis by overexpressing PsbP and PsiK genes, promoting photosynthetic electron transfer and activating PSII and PSI in N. benthamiana} Photosynthesis is the key reaction to sustain life. In higher plants, oxygenic photosynthesis takes place in chloroplasts, in which protein complexes involved in the light-harvesting and photosynthetic electron transport 
Table 1 Primer sequences of the genes involved in photosynthesis used for qRT-PCR analysis

\begin{tabular}{llll}
\hline Gene ID & Length $(\mathbf{b} \mathbf{p})$ & Primer- $\mathbf{F}\left(\mathbf{5}^{\prime} \mathbf{-} \mathbf{3}^{\prime} \mathbf{)}\right.$ & Primer- $\mathbf{n}\left(\mathbf{5}^{\prime} \mathbf{-} \mathbf{3}^{\prime} \mathbf{)}\right.$ \\
\hline PsbP & 138 & GCTCTCACTGTCCTCATT & GAATCCATCTCCGTTGTATG \\
PsbS1 & 124 & CTATGAAGCAGAGCCACTA & AGCCTTATCAAGACCAGTAG \\
Psi-K & 121 & CCATCAGCAAACAGGAAG & GACCAACAACACCACAAG \\
PsbQ1 & 129 & TCGTCTCAGAGCAGAATAC & GCATGGTCCAGATCACTA \\
PsbQ2 & 112 & ACCGTCATCTCTGCTAAG & GGCTGTTCTTGGTCTTTG \\
PsbO4 & 174 & GTTCCTTGTGCCATCATAC & CTCAGCGTGATCTTACCT \\
PsbY & 153 & GACATAGCAGAAGGAGACA & ACCAGTAAGACCAAGACC \\
HCF136 & 103 & GCATTCTTATGTCGGCTAC & GTCACGAATCCATGTCTTG \\
GAPDH & 125 & AGCTCAAGGGAATTCTCGATG & AACCTTAACCATGTCATCTCCC \\
\hline
\end{tabular}
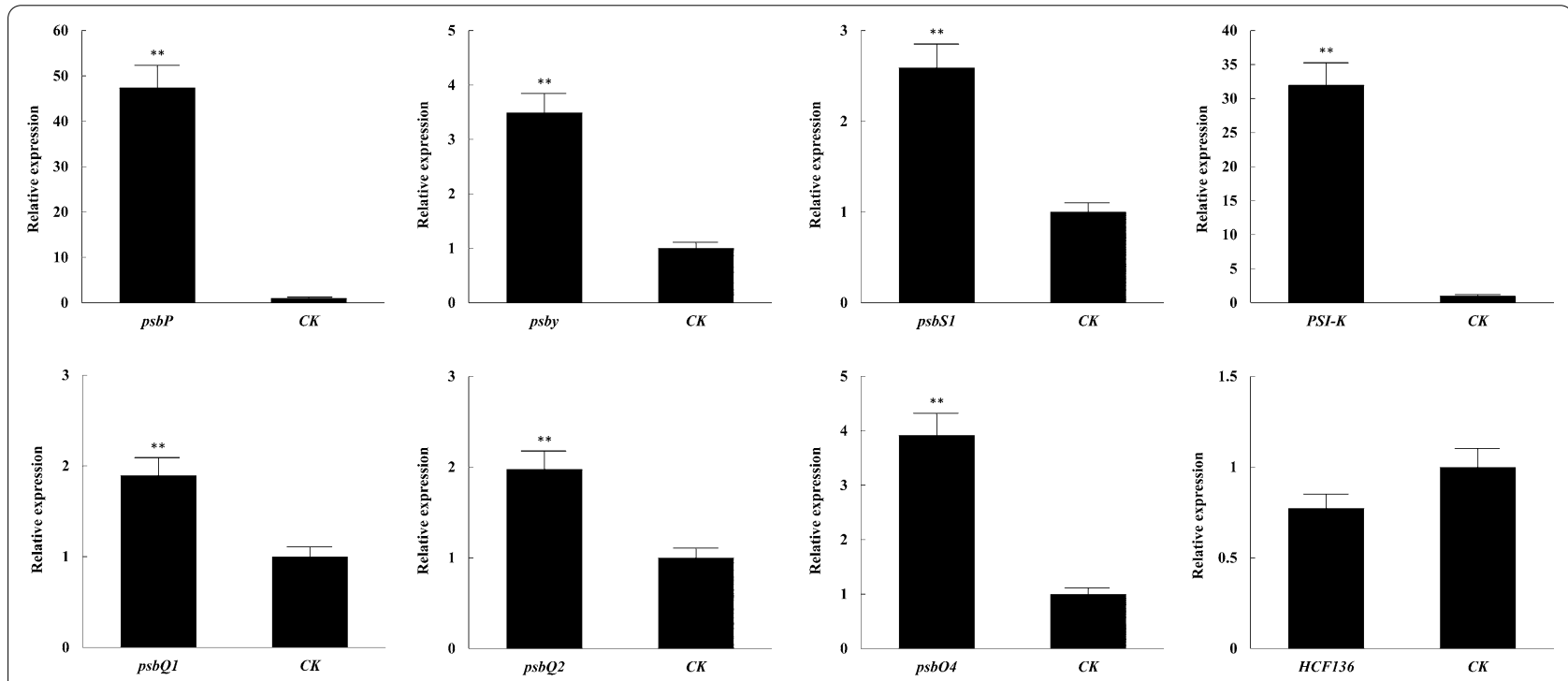

Fig. 7 The relative transcript level of eight major photosynthetic genes exposure to $0.05 \mathrm{mg} / \mathrm{mL}$ NIR-CDs after 5 days duration of incubation. Marked with ${ }^{*} P<0.05{ }^{*} P<0.01$ exhibit significant differences from the control, respectively
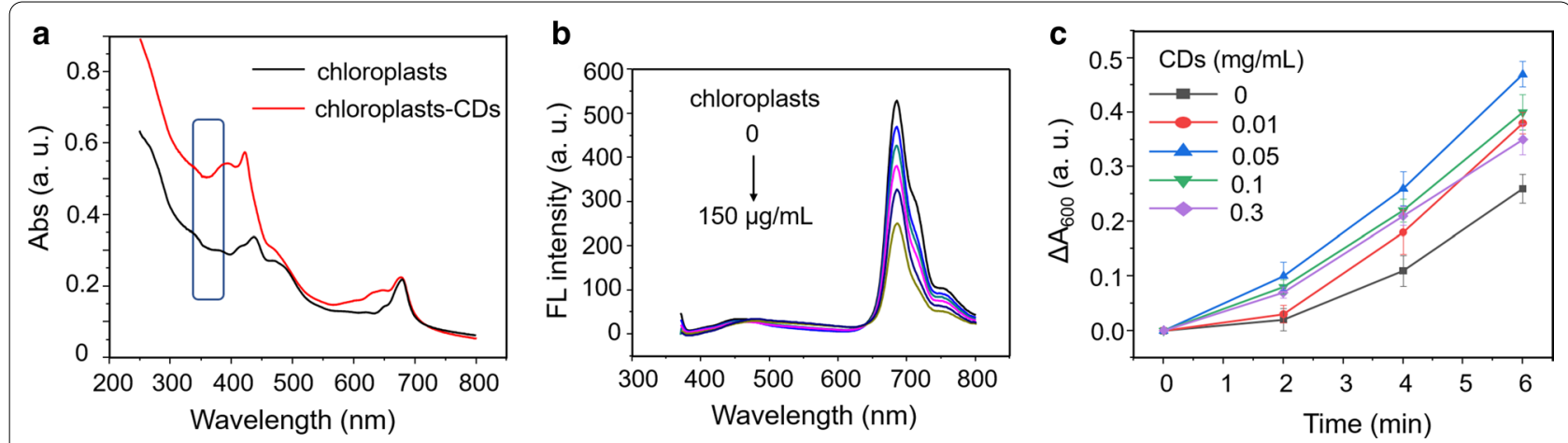

Fig. 8 a Absorption spectra of chloroplast suspension $(100 \mu \mathrm{g} / \mathrm{mL}$ ) and the chloroplast-CDs complex (NIR-CDs: $50 \mu \mathrm{g} / \mathrm{mL}$ ). b Fluorescence emission spectra (excitation wavelength: $380 \mathrm{~nm}$ ) of the CDs $(5 \mu \mathrm{g} / \mathrm{mL})$ in the presence of different amounts of chloroplast $(0,5,10,15,20$ and $30 \mathrm{\mu g} / \mathrm{mL})$. c DCPIP reductions upon the addition of varying concentrations of NIR-CDs $(0,0.01,0.05,0.1 \mathrm{and} 0.3 \mathrm{mg} / \mathrm{mL})$ in the CDs-chloroplast complexes under the light intensity of $4 \mathrm{~mW} / \mathrm{cm}^{2}$ 
are located in thylakoid membranes. Two light-energy driven photosystems (PS), PSI and PSII, are key components of photosynthetic electron transport machinery [49].

Photosystem I (PSI) is a supramolecular complex consisting of 17 different polypeptides located in the higher plant membranes. PSI-K is a subunit of photosystem $\mathrm{I}$, and is significant for organizing the peripheral lightharvesting complexes on the core antenna of PSI [50]. In the present study, the expression levels of PsiK gene were dramatically increased by 32 -fold as compared to the control. The results suggested that $P s i K$ also played a key role in response to the growth-promoting effect of NIR-CDs.

Molecular oxygen metabolism is vital for photosynthesis, which is generated mainly by photosystem II (PS II). Photosystem II (PSII) is a light-driven water-plastoquinone oxidoreductase, in which the oxygen-evolving complex (OEC) catalyzes the water-splitting reaction [51].

It is known that some membrane-extrinsic subunits associated to the lumenal side of PSII in higher plants, including $P s b O, P s b P, P s b Q$, and $P s b R$, play crucial roles in optimizing water-oxidizing activity [52]. Some studies about $P s b P$-lacking transgenic plants suggested that $P s b P$ was essential for full PSII function and chloroplast development [53]. In PsbP-deficient $N$. tabacum, PSII was hypersensitive to light and rapidly inactivated when the repair process of damaged PSII was inhibited. Moreover, the manganese cluster of $P s b P$-deficient leaves was markedly unstable. Another study on $A$. thaliana where both $P s b Q$ genes (psbQ-1 and psbQ-2) had been suppressed, demonstrated that $P s b Q$ was indispensable for photoautotrophy under low-light stress [54]. Kakiuchi et al. confirmed that $P s b Q$ could significantly compensate for functional defects of mutated PsbPs, suggesting that $P s b Q$ had a role in stabilizing the functional binding of $P s b P$ in higher plant PSII [51].

$P s b P$ and $P s b Q$ were shown to play different roles in PSII of plants, including the likelihood that $P s b P$ was in closer association to the oxygen-evolving catalytic center, $P s b Q$ might not be required for PSII assembly, but should be involved in stabilizing the binding of PsbP [49]. Suppression of $P s b P$ might lead to a reduction in growth rate and a wide range of defects in PSII function, such as lower quantum yield, lower oxygen-evolving activity, and a slower electron transfer rate at the donor side of PSII [55]. However, the suppression of PsbQ did not result in the severe malfunction of PSII in Arabidopsis [54]. These results suggested that $P s b Q$ might play a less important role in PSII of higher plant than PsbP.

Similar to these previous studies, in the present study, the expression levels of $P s b P$ gene were increased the most by 48 -fold as compared to the control, and it was far higher than the expression levels of $P s b Q 1$ and $P s b Q 2$. The results also indicated that $P s b P, P s b Q 1$, and $P s b Q 2$ were the regulatory genes involved in PSII in response to the stimulation effect of NIR-CDs, especially $P s b P$ was the dominant regulator for the growthpromoting effect of NIR-CDs.

A study on high chlorophyll fluorescence (HCF) photosynthetic mutants of Arabidopsis led to the identification of HCF136. It was a nucleus-encoded assembly factor, which was essential for assembly or stability of the PSII reaction center complex, and might function as a chaperone-like assembly factor. HCF136 was also reported to be required for efficient repair of PSII in Synechocystis [56]. On the contrary, another HCF136 homologue was reported to be needless for assembly of the PSII, and hence was not required for photoautotrophic growth of Synechococcus PCC 7002 [57]. In the present study, no significant changes in the expression level of HCF136 gene were observed in response to the stimulating photosynthesis effect of NIR-CDs, which also indicated that HCF136 was not closely associated with photoautotrophy of $N$. benthamiana.

Previously, far-red emissive CDs (FR-CDs) have been synthesized and applied for enhanced sunlight absorption and photosynthesis efficiency [36]. The as-prepared FR-CDs was an efficient converter transferring ultraviolet A (UV-A) light to $625-800 \mathrm{~nm}$ farred emission, which could be directly absorbed and utilized by chloroplasts. The in vivo experiment demonstrated $51.14 \%$ enhancement of fresh weights compared with that of the control group. Compared with the FR-CDs, the proposed NIR-CDs showed similar absorption range, but relatively narrow emission band $(625-720 \mathrm{~nm})$. Due to the better spectrum overlap between the NIR-CDs emission and the absorption of chloroplast $(640-710 \mathrm{~nm})$, much more photons were absorbed and transferred to chloroplast, and thereby improving the photosynthesis [58]. Aa a result, the enhancement of fresh weight reached to $247.03 \%$, nearly five times than that of FR-CDs-caused weight enhancement. Moreover, in this work, it is the first report on the mechanism research in the molecular level of genes. It would provide a manner to study the interaction mechanism between luminescent nanomaterials and photosynthesis-related genes. A detailed comparison on optical properties, fresh weight enhancement, toxicity and mechanism between this work and previous reports is summarized in Additional file 1: Table S1. As shown therein, the proposed NIRCDs show overall advantages compared to the previous luminescent nanomaterials. 


\section{Conclusion}

In summary, NIR emissive CDs were successfully adopted for enhanced photosynthesis both in vitro and in vivo, and the activation mechanism was further illustrated by gene analysis. The CDs with good mono-dispersity and hydrophily were easily prepared by a one-step microwave-assisted carbonization manner. The obtained NIRCDs showed obvious absorption in the UV region, strong and stable far-red fluorescence emission. The hybridized chloroplast-CDs complexes revealed effective absorption in UV region and accelerated the electron transfer from photosystem II (PS II) to photosystem I (PS I). NIRCDs exhibited a concentration-dependent promotion effect on $N$. benthamiana growth, and it was achieved by strengthening photosynthesis. Seven photosynthetic genes and chloroplast synthesis related genes were demonstrated to be closely related to the photosynthesisstimulating effect, among which $P s b P$ and $P s i K$ genes were the key regulators. The results in this work revealed the underlying molecular responders in response to NIRCDs treatment. This result could provide a theoretical basis for expanding the applications of nanomaterial in sustainable agriculture practices.

\section{Materials and methods}

\section{Materials and apparatus}

Reduced glutathione, $\mathrm{Na}_{2} \mathrm{HPO}_{4}, \mathrm{KH}_{2} \mathrm{PO}_{4}$ and $\mathrm{KCl}$ were obtained from Aladdin Chemistry Co., Ltd (Shanghai, China). Sucrose, formamide and 2,6-dichlorophenolindophenol (DCPIP) were purchased from Sinopharm Chemical Reagent Co., Ltd. (Shanghai, China). All reagents were used as received without further purification. All aqueous solutions were prepared using deionized (DI) water.

A microwave oven [Galanz, P70F20CL-DG(B0)] was employed for the synthesis of CDs. The sizes and morphologies of the CDs were characterized by high resolution transmission electron microscopy (HR-TEM) (Tecnai F20) with an acceleration voltage of $200 \mathrm{kV}$. Fourier transform infrared (FT-IR) spectrum was performed on a Nicolet 6700 FT-IR spectrometer via the KBr pellet method. X-ray photoelectron spectroscopy (XPS) measurements were performed on a ESCALAB 250Xi (Thermo Scientific). The crystal phase of NIR-CDs was identified by a Bruker D8 Discover X-ray diffractometer (XRD) with $2 \theta$ range from $10^{\circ}$ to $50^{\circ}$ at a scanning rate of $4^{\circ} / \mathrm{min}$, with $\mathrm{Cu} \mathrm{Ka}$ irradiation $(\mathrm{k}=1.5406 \AA)$. Raman spectrum was recorded on a Renishaw inVia Raman spectrophotometer using $532 \mathrm{~nm}$ laser as the excitation resource. Fluorescence excitation and emission spectra were recorded on a Perkin Elmer spectrophotometer (LS-55). UV-Vis absorption were obtained from a
Agilent Cary 300 spectrophotometer. Fluorescence lifetimes were measured by Fluorolog 3-11 (HORIBA Jobin Yvon). Absolute fluorescence quantum yield of the CDs was determined by a Fluoromax-4 measurement system (HORIBA, JobinYvon. Inc).

\section{Preparation of NIR-CDs}

The CDs were synthesized via a one-step microwaveassisted carbonization manner [36, 59]. In brief, reduced glutathione $(0.5 \mathrm{~g})$ was dissolved in $20 \mathrm{~mL}$ formamide under ultrasonic treatment for $5 \mathrm{~min}$. Subsequently, the mixture was transferred into a domestic microwave oven $(700 \mathrm{~W})$ for $3 \mathrm{~min}$. After being cooled down to room temperature naturally, the obtained dark green solution was centrifuged at 10,000 rpm for $5 \mathrm{~min}$ to remove largesized nanoparticles, and purified by a dialysis of 5 days (cut-off molecular weight, 3500). Then, the CDs solution was dried by a rotary evaporation to remove water. Finally, the product i.e., dark green NIR-CDs powder was harvested.

\section{Isolation of chloroplasts}

Chloroplasts were extracted from fresh leaves of tobacco that planted in our lab. The procedures were performed according to the previous literature [38]. Briefly, $5 \mathrm{~g}$ fresh leaves were cleaned by water and cut into small pieces, and then transferred into sucrose buffer $(0.4 \mathrm{M}$ sucrose, $0.03 \mathrm{M} \mathrm{Na}_{2} \mathrm{HPO}_{4}, 0.02 \mathrm{M} \mathrm{KH}_{2} \mathrm{PO}_{4}$ and $0.01 \mathrm{M} \mathrm{KCl}, \mathrm{pH}$ 7.7). After a quick grind of $5 \mathrm{~min}$, the filtrate was centrifuged at $1000 \mathrm{rpm}$ for $3 \mathrm{~min}$ to remove large residues. And the supernatant was collected and centrifuged at $3000 \mathrm{rpm}$ for $3 \mathrm{~min}$. Finally, the precipitate was collected and re-dispersed in $5 \mathrm{~mL}$ sucrose buffer to obtain a chloroplast suspension with the concentration calculated to be ca. $2.0 \mathrm{mg} / \mathrm{mL}$. All the operations were carried out in the dark at $0-4{ }^{\circ} \mathrm{C}$.

\section{Fabrication of the CDs/chloroplast complex}

To acquire the complex of CDs-chloroplast, a simple mix between NIR-CDs and chloroplast suspension was performed in the sucrose buffer for $0.5 \mathrm{~h}$ at $4{ }^{\circ} \mathrm{C}$. The CDs would interact with chloroplasts, and were adsorbed onto the surface of chloroplasts and then form the CDs/ chloroplast complexes.

\section{Plant cultivation and NIR-CDs treatment}

Nicotiana benthamiana ( $N$. benthamiana) seeds were germinated in dark and moist conditions for 3 days. The germinated seeds were transferred into planting cups and cultured in a greenhouse $\left(25 \pm 2{ }^{\circ} \mathrm{C}, 60 \%\right.$ relative humidity, $400 \mu \mathrm{mol} / \mathrm{m} / \mathrm{s}$ light intensity, $16 \mathrm{~h}$ light $/ 8 \mathrm{~h}$ dark photoperiod). Then, seedlings in six-leaf stage showing consistent growth were selected and uniformly 
divided into five groups. NIR-CDs solutions at $0.01 \mathrm{mg} /$ $\mathrm{mL}, 0.05 \mathrm{mg} / \mathrm{mL}, 0.1 \mathrm{mg} / \mathrm{mL}, 0.3 \mathrm{mg} / \mathrm{mL}$ were sprayed on seedlings with a dosage of $20 \mathrm{~mL} /$ pot on the second day after transplantation, and $20 \mathrm{ml}$ of ultrapure water was sprayed as the control. Phenotypic changes were observed and recorded for the next 5 days. Each treatment was repeated three times with ten plants.

\section{Growth potential index determination}

The root length, stem length, leaf area and single plant fresh weight (FW) of $10 \mathrm{~N}$. benthamiana seedlings from each concentration of NIR-CDs treatment were measured after 5 days. Fresh weight was determined by gravimetric method. Growth rate of single plant fresh weight was expressed as percent $(\%)=($ single plant fresh weight of treatment group sample - single plant fresh weight of control group sample)/single plant fresh weight of control group sample $\times 100 \%$. The top two leaves of 10 seedlings from each treatment were collected for the measurement of leaf area.

The activity of superoxide dismutase (SOD) was determined according to our previous report [40] by following the photo-reduction of nitroblue tetrazolium (NBT) at $560 \mathrm{~nm}$.

\section{Uptake and translocation of NIR-CDs visualized by laser confocal}

Laser confocal images were obtained from $N$. benthamiana seedlings after 5 days of treatment to track the fluorescence of CDs. The complete part of the root tip, blade back of leaves without veins, and the transection of stem were selected for preparing seedling tissue sections by hand-slicing. Then the tissue sections were placed into clean glass slides, followed by covering with a cover slip for fixation. Subsequently, thin slices of different parts (root, stem and leaf) of the plants were observed by Leica laser scanning confocal microscopy (LEICA TCS SP8, GER) excited at $488-587 \mathrm{~nm}$ to identify the locations of NIR-CDs [50].

\section{Photosynthetic efficiency and pigment measurement}

$N$. benthamiana seedlings treated with $0.05 \mathrm{mg} / \mathrm{mL}$ of NIR-CDs solution were sampled and determined in seven-leaf, ten-leaf, and thirteen-leaf stage, respectively. Net photosynthetic rate $(\mathrm{Pn})$, transpiration rate $(\mathrm{Tr})$, stomatal conductance (Cond), and mesophyll intercellular $\mathrm{CO}_{2}(\mathrm{Ci})$ were measured using LI-6400 portable photosynthesis meter (Li-COR company, USA) according to a reported method [40]. The total chlorophyll $(\mathrm{Chl} \mathrm{a}+\mathrm{b})$ contents of $N$. benthamiana leaves were measured using SPAD (Special Products Analysis Division) $-5022^{\circledR}$ plus chlorophyll meter (Minolta Camera Co., Osaka, Japan).

\section{Quantitative qPCR analysis of the genes involved in photosynthesis}

Based on the above photosynthetic physiological indexes, NIR-CDs solutions at $0.05 \mathrm{mg} / \mathrm{mL}$ was the optimal treatment concentration. After a treatment of 5 days, the leaves of $0.05 \mathrm{mg} / \mathrm{mL}$ NIR-CDs treatment were frozen quickly with liquid nitrogen, and the seedlings sprayed with ultrapure water were used as control. The total RNA in these leaves was extracted and reverse-transcribed to cDNA using a Plant Total RNA Reagent (Invitrogen) and TransScript All-in-One First-Strand cDNA Synthesis SuperMix for qPCR (TransGen Biotech, Beijing, China) following the manufacturer's protocol, respectively. The genes expression levels of PSI-K (AY899937.1) in photosystem I, psbP (KF460578.1), psbS1 (EU645483.1), psbY (EH369921.1), HCF136 (EH364276.1) in photosystem II, and psbQ1 (JF897611.1), psbQ2 (JF89761 2.1), psbO4 (JF897606.1) for precursors of chloroplasts synthesis were measured by quantitative real-time (qRT)-PCR analysis using GAPDH as an internal reference. The genes sequences were retrieved from National Center for Biotechnology Information (https://www.ncbi.nlm.nih.gov/) to design primers (Table 1) using Primer Premier software, version 5 . Each reaction contained $1 \mu \mathrm{L}$ of cDNA, $5 \mu \mathrm{L}$ of $2 \times$ Power SYBR green PCR master mix (Applied Biosystems, Forster City, CA, USA), and $1 \mu \mathrm{L}$ of forward and reverse primers in a final volume of $10 \mu \mathrm{L}$. Finally, the relative gene expression level was calculated using the $2^{-\triangle \Delta C T}$ method. Dissociation-curve analysis was carried out to confirm the amplification specificity. Three technical replicates were performed for each sample.

\section{Statistical analysis}

All experiments results were expressed as means \pm standard deviation (SD). Statistical significance of all data was determined using a one-way analysis of variance (ANOVA) and the significance between treatments was assessed by LSD multiple comparison test at $P<0.05$.

\section{Supplementary Information}

The online version contains supplementary material available at https://doi. org/10.1186/s12951-021-01005-0.

Additional file 1: Figure S1. Raman spectrum of the NIR-CDs. Figure S2. High resolution XPS spectra of C $1 \mathrm{~s}(\mathrm{a}), \mathrm{N} 1 \mathrm{~s}$ (b), O $1 \mathrm{~s}(\mathrm{c})$ and S2p (d), respectively. Figure $\mathbf{S 3}$. Zeta potential measurement of the NIR-CDs. Figure S4. FL decay fitting curve of the NIR-CDs $(10 \mu \mathrm{g} / \mathrm{mL})$ in water $\left(\lambda_{\mathrm{ex}}=420 \mathrm{~nm}, \lambda_{\mathrm{em}}=680 \mathrm{~nm}\right)$. Figure S5. Photostability measurement of the CDs $(10 \mu \mathrm{g} / \mathrm{mL}$, relative intensities recorded at $680 \mathrm{~nm})$ under continuous UV-light irradiation. Figure S6. The storage stability assessment of the CDs $(100 \mu \mathrm{g} / \mathrm{mL})$ in aqueous solution. Table S1. A detailed comparison on optical properties, toxicity and mechanism between this work and previous reports. 


\section{Authors' contributions}

Experiments were designed by XP and JPZ and conducted by YHW, ZMX, and XHW. Data was analysed by ZMX. Manuscript was prepared by YHW, XP and edited by JPZ. All authors read and approved the final manuscript.

\section{Funding}

This work was financially supported by Zhejiang Provincial Natural Science Foundation (LY20B050003), Ningbo Science and Technology Bureau (2016C50009, 2018B10054), and the Ningbo 3315 Innovation Teams Program (2019A-14-C)

\section{Availability of data and materials}

The genes sequences of $\mathrm{N}$. benthamiana were retrieved from National Center for Biotechnology Information (https://www.ncbi.nlm.nih.gov/). Complementary data of CDs are supplied as Additional file 1.

\section{Declarations}

Ethics approval and consent to participate

Not applicable.

\section{Consent for publication}

All Authors have agreed to submit it in its current form for consideration for publication in your journal.

\section{Competing interests}

There are no conflicts to declare.

\section{Author details}

${ }^{1}$ Cixi Institute of Biomedical Engineering, Ningbo Institute of Materials Technology and Engineering, Chinese Academy of Sciences, Ningbo 315300, People's Republic of China. ${ }^{2}$ Ningbo Research Institute of Zhejiang University, Ningbo 315100, People's Republic of China. ${ }^{3}$ Fujian Agriculture and Forestry University, Fuzhou 350028, People's Republic of China.

Received: 29 June 2021 Accepted: 18 Auqust 2021

Published online: 28 August 2021

\section{References}

1. Oleńska E, Małek W, Wójcik M, Swiecicka I, Thijs S, Vangronsveld J. Beneficial features of plant growth-promoting rhizobacteria for improving plant growth and health in challenging conditions: a methodical review. Sci Total Environ. 2020;743: 140682.

2. Rodríguez H, Fraga R, Gonzalez T, Bashan Y. Genetics of phosphate solubilization and its potential applications for improving plant growthpromoting bacteria. Plant Soil. 2006;287:15.

3. Uga Y, Kitomi Y, Ishikawa S, Yano M. Genetic improvement for root growth angle to enhance crop production. Breeding Sci. 2015;65(2):111.

4. Mercedes R, Romero-Aranda MR, Jurado O, Cuartero J. Silicon alleviates the deleterious salt effect on tomato plant growth by improving plant water status. J Plant Physiol. 2006;163(8):847.

5. Mickens MA, Torralba M, Robinson SA, Spencer LE, Romeyn MW, Massa GD, Wheeler RM. Growth of red pak choi under red and blue, supplemented white, and artificial sunlight provided by LEDs. Sci Hortic. 2019;245:200

6. Lin X, Li Y, Saravanakumar S, Tang Q, Zhang S, Gao X, Hu Y, Huang K, Han G. Sunlight-operable light converting smart windows for fertilizer-free plant growth enhancement. Nano Today. 2020;34: 100918.

7. Guo Z, Park S, Yoon J, Shin I. Recent progress in the development of nearinfrared fluorescent probes for bioimaging applications. Chem Soc Rev. 2014;43:16

8. Yu J, Yu H, Li L, Ni X, Song K, Wang L. Influence of luminescent nanomaterials on plant growth and development. ChemNanoMat. 2021;7:859.

9. Li X-B, Tung C-H, Wu L-Z. Semiconducting quantum dots for artificial photosynthesis. Nat Rev Chem. 2018;2:160.

10. Li Y, Li W, Zhang H, Liu Y, Ma L, Lei B. Amplified light harvesting for enhancing Italian lettuce photosynthesis using water soluble silicon quantum dots as artificial antennas. Nanoscale. 2020;12:155.
11. Dong R, Li Y, Li W, Zhang H, Liu Y, Ma L, Wang X, Lei B. Recent developments in luminescent nanoparticles for plant imaging and photosynthesis. J Rare Earth. 2019:37:903.

12. Gautam A, Gore PM, Kandasubramanian B. Nanocluster materials in photosynthetic machines. Chem Eng J. 2020;385: 123951.

13. Tsoi KM, Dai Q, Alman BA, Chan WCW. Are quantum dots toxic? Exploring the discrepancy between cell culture and animal studies. Acc Chem Res. 2013;46:662.

14. Li Q, Zeman CJ IV, Ma Z, Schatz GC, Gu XW. Bright NIR-II photoluminescence in rod-shaped icosahedral gold nanoclusters. Small. 2021;17: 2007992.

15. Gong Y, Zhao J. Small carbon quantum dots, large photosynthesis enhancement. J Agric Food Chem. 2018;66(35):9159.

16. Wang B, Song H, Qu X, Chang J, Yang B, Lu S. Carbon dots as a new class of nanomedicines: opportunities and challenges. Coord Chem Rev. 2021:442: 214010

17. Zulfajri M, Abdelhamid HN, Sudewi S, Dayalan S, Rasool A, Habib A, Huang GG. Plant part-derived carbon dots for biosensing. Biosensors. 2020;10:68

18. Abdelhamid HN, Talib A, Wu HF. One pot synthesis of gold-carbon dots nanocomposite and its application for cytosensing of metals for cancer cells. Talanta. 2017;166:357.

19. Abdelhamid HN, Wu HF. Polymer dots for quantifying the total hydrophobic pathogenic lysates in a single drop. Colloids Surf B Biointerfaces. 2014:115:51.

20. Wan J, Zhang X, Zhang K, Su Z. Biological nanoscale fluorescent probes: from structure and performance to bioimaging. Rev Anal Chem. 2020;39:209.

21. Goel S, Mishra P. Thymoquinone loaded mesoporous silica nanoparticles retard cell invasion and enhance in vitro cytotoxicity due to ROS mediated apoptosis in HeLa and MCF-7 cell lines. Mater Sci Engineer C. 2019:104: 109891

22. Li K, Zhao X, Wei G, Su Z. Recent advances in the cancer bioimaging with graphene quantum dots. Curr Med Chem. 2018;25:2876.

23. Lim S, Shen W, Gao Z. Carbon quantum dots and their applications. Chem Soc Rev. 2015:44:362.

24. Zhang M, Cheng J, Hu J, Luo J, Zhang Y, Lu F, Kong H, Qu H, Zhao Y. Green Phellodendri Chinensis Cortex-based carbon dots for ameliorating imiquimod-induced psoriasis-like inflammation in mice. J Nanobiotechnol. 2021;19:105

25. Wang W, Cheng L, Liu G. Biological applications of carbon dots. Sci China Chem. 2014:57:522.

26. Havrdova M, Hola K, Skopalik J, Tomankova K, Petr M, Cepe K, Polakova K, Tucek J, Bourlinos AB, Zboril R. Toxicity of carbon dots-effect of surface functionalization on the cell viability, reactive oxygen species generation and cell cycle. Carbon. 2016;99:238.

27. Chaudhary S, Umar A, Bhasin KK, Singh S. Applications of carbon dots in nanomedicine. J Biomed Nanobiotech. 2017;13:591.

28. Wang $H$, Zhang M, Song Y, Li H, Huang H, Shao M, Liu Y, Kang Z. Carbon dots promote the growth and photosynthesis of mung bean sprouts. Carbon. 2018:136:94

29. Lia Y, Pan X, Xu K, Wu Y, Zhuang J, Zhang X, Zhang H, Lei B, Hu C, Liu Y. Carbon dots as light converter for plant photosynthesis: augmenting light coverage and quantum yield effect. J Hazardous Mater. 2021;410: 124534.

30. Budak E, Erdoğan D, Ünlü C. Enhanced fluorescence of photosynthetic pigments through conjugation with carbon quantum dots. Photosynth Res. 2021;147:1.

31. Li Y, Xu X, Wu Y, Zhuang J, Zhang X, Zhang H, Lei B, Hu C, Liu Y. A review on the effects of carbon dots in plant systems. Mater Chem Front. 2020;4:437

32. Tan TL, Zulkifli NA, Zamana ASK, Jusoh MB, Yaapar MN, Rashid SA. Impact of photoluminescent carbon quantum dots on photosynthesis efficiency of rice and corn crops. Plant Physiol Biochem. 2021:162:737.

33. Chakravarty D, Erande MB, Late DJ. Graphene quantum dots as enhanced plant growth regulators: effects on coriander and garlic plants. J Sci Food Agric. 2015;95(13):2772

34. Chandra S, Pradhan S, Mitra S, Patra P, Bhattacharya A, Pramanik P, Goswami A. High throughput electron transfer from carbon dots to chloroplast: a rationale of enhanced photosynthesis. Nanoscale. 2014;6:3647. 
35. Li W, Wu S, Zhang H, Zhang X, Zhuang J, Hu C, Liu Y, Lei B, Ma L, Wang $X$. Enhanced biological photosynthetic efficiency using light-harvesting engineering with dual-emissive carbon dots. Adv Funct Mater. 2018;28:1804004.

36. Li DN, Li W, Zhang HR, Zhang XJ, Zhuang JL, Liu YL, Hu CF, Lei BF. Far-Red carbon dots as efficient light-harvesting agent for enhanced photosynthesis. ACS Appl Mater Interfaces. 2020;12(18):21009.

37. Li W, Zheng YJ, Zhang HR, Liu ZL, Su W, Chen S, Liu YL, Zhuang JL, Lei BF. Phytotoxicity, uptake and translocation of fluorescent carbon dots in mung bean plants. ACS Appl Mater Interfaces. 2016;8(31):19939.

38. Nimi N, Ariya S, Shaiju SN, Nimmi F, Sachin JS, Ramapurath SJ. Multifunctional hybrid nanoconstruct of zerovalent iron and carbon dots for magnetic resonance angiography and optical imaging: an in vivo study. Biomaterials. 2018;171:46.

39. Dresselhaus MS, Jorio A, Hofmann M, Dresselhaus G, Saito R. Perspectives on carbon nanotubes and graphene raman spectroscopy. Nano Lett. 2010;10:751.

40. Li YJ, Li W, Zhang HR, Dong RY, Li DN, Liu YL, Huang L, Lei BF. Biomimetic preparation of silicon quantum dots and its phytophysiology effect on cucumber seedling. J Mater Chem B. 2019;7(7):1107.

41. Song W, Liu YX, Fanady B, Han YF, Xie L, Chen ZY, Yu KB, Peng X, Zhang XL, Ge ZY. Ultra-flexible light-permeable organic solar cells for the herbal photosynthetic growth. Nano Energy. 2021;86: 106044.

42. Pan L, Sun S, Zhang L, Jiang K, Lin H. Near-infrared emissive carbon dots for two-photon fluorescence bioimaging. Nanoscale. 2016;8:17350.

43. Bojdys MJ, Müller JO, Antonietti M, Thomas A. lonothermal synthesis of crystalline, condensed, graphitic carbon nitride. Chem Eur J. 2008; 14:8177.

44. Qu D, Zheng M, Du P, Zhou Y, Zhang L, Li D, Tan H, Zhao Z, Xie Z, Sun Z. Highly luminescent S, N co-doped graphene quantum dots with broad visible absorption bands for visible light photocatalysts. Nanoscale. 2013;5:12272.

45. Liu J, Geng Y, Li D, Yao H, Huo Z, Li Y, Zhang K, Zhu S, Wei H, Xu W, Jiang J, Yang B. Deep red emissive carbonized polymer dots with unprecedented narrow full width at half maximum. Adv Mater. 2020;32:1906641.

46. Zhen S, van lersel MW. Far-red light is needed for efficient photochemistry and photosynthesis. J Plant Physiol. 2017;209:115.

47. Park S, Steen CJ, Lyska D, Fischer AL, Endelman B, Iwai M, Niyogi KK, Fleming GR. Chlorophyll-carotenoid excitation energy transfer and charge transfer in Nannochloropsis oceanica for the regulation of photosynthesis. Proc Nat Acad Sci USA. 2019;1 16(9):3385.

48. Eyster C, Brown TE, Tanner HA, Hood SL. Manganese requirement with respect to growth, hill reaction and photosynthesis. Plant Physiol. 1958;33(4):235.
49. Ifuku K. The PsbP and PsbQ family proteins in the photosynthetic machinery of chloroplasts. Plant Physiol Biochem. 2014;81:108.

50. Jensen PE, Gilpin M, Knoetzel JR, Scheller HV. The PSI-K subunit of photosystem I is involved in the interaction between light-harvesting complex I and the photosystem I reaction center core. J Biol Chem. 2000;275(32):24701

51. Shusuke K, Uno C, Ido K, Nishimura TS, Noguchi T, Ifuku K, Sato F. The PsbQ protein stabilizes the functional binding of the PsbP protein to photosystem II in higher plants. Biochim Biophys Acta. 2012;1817(8):1346

52. Bricker TM, Roose JL, Fagerlund RD, Frankel LK, Eaton-Rye JJ. The extrinsic proteins of photosystem II. Biochim Biophys Acta. 2011;1817(1):121.

53. Sandhu D, Atkinson T, Noll A, Johnson C, Espinosa K, Boelter J, Abel S, Balpreet KD, Barta T, Singsaas E, Sepsenwol S, Goggi AS, Palmer RG. Soybean proteins GmTic1 10 and GmPsbP are crucial for chloroplast development and function. Plant Sci. 2016;252:76.

54. Yi X, Hargett SR, Frankel LK, Bricker TM. The PsbQ protein is required in Arabidopsis for photosystem II assembly/stability and photoautotrophy under low light conditions. J Biol Chem. 2006;281:26260.

55. Bricker TM, Frankel LK. Auxiliary functions of the PsbO, PsbP and PsbQ proteins of higher plant photosystem II: a critical analysis. J Photochem Photobiol B. 2011;104(1-2):165.

56. Komenda J, Nickelsen J, Tichy M, Prasin O, Eichacker LA, Nixon PJ. The cyanobacterial homologue of HCF 136/YCF48 is a component of an early photosystem II assembly complex and is important for both the efficient assembly and repair of photosystem II in Synechocystis sp. PCC 6803. J Biol Chem. 2008;283(33):22390.

57. Shen G, Zhao J, Reimer SK, Antonkine ML, Cai Q, Weiland SM, Golbeck JH, Bryant DA. Assembly of photosystem I. I. Inactivation of the rubA gene encoding a membrane-associated rubredoxin in the cyanobacterium Synechococcus sp. PCC 7002 causes a loss of photosystem I activity. J Biol Chem. 2002:277(23):20343.

58. Lin S, Bhattacharya P, Rajapakse NC, Brune DE, Ke PC. Effects of quantum dots adsorption on algal photosynthesis. J Phys Chem C. 2009:1 13:10962

59. Qian S, Qiao L, Xu W, Jiang K, Wang Y, Lin H. An inner filter effect-based near-infrared probe for the ultrasensitive detection of tetracyclines and quinolones. Talanta. 2019. https://doi.org/10.1016/j.talanta.2018.10.097.

\section{Publisher's Note}

Springer Nature remains neutral with regard to jurisdictional claims in published maps and institutional affiliations.
Ready to submit your research? Choose BMC and benefit from:

- fast, convenient online submission

- thorough peer review by experienced researchers in your field

- rapid publication on acceptance

- support for research data, including large and complex data types

- gold Open Access which fosters wider collaboration and increased citations

- maximum visibility for your research: over $100 \mathrm{M}$ website views per year

At BMC, research is always in progress.

Learn more biomedcentral.com/submissions 